\title{
Research on Interpreting Pedagogy in Multimedia Environment
}

\author{
Lin Tian \\ School of Foreign Languages, Sichuan University of Arts and Science, Dazhou, China \\ Email: tianlin1984@126.com
}

How to cite this paper: Tian, L. (2018). Research on Interpreting Pedagogy in Multimedia Environment. Advances in Literary Study, 6, 153-160.

https://doi.org/10.4236/als.2018.63013

Received: July 18, 2018

Accepted: July 28, 2018

Published: July 31, 2018

Copyright $\odot 2018$ by author and Scientific Research Publishing Inc. This work is licensed under the Creative Commons Attribution International License (CC BY 4.0).

http://creativecommons.org/licenses/by/4.0/

\section{(c) (i) Open Access}

\begin{abstract}
In the present multimedia environment, the traditional teacher-lecturing or information-delivering teaching mode is still frequently adopted, even though the flipped teaching mode has drawn increasing attention from the scholars and teachers. Against this backdrop, a research on the adoption of interpreting pedagogy has been done to see the students' preference over the traditional and the flipped teaching mode and explore the possible reasons behind this preference. The research findings indicate that the participants favor the flipped interpreting teaching mode more than the traditional lecturing mode, mainly because this can save them more in-class time for interactive interpreting activities and for more tutor's instructions. Therefore, a mode for flipped interpreting teaching is suggested for further experiment, covering three modules, namely, pre-class online learning, in-class instruction and practice and after-class tasks.
\end{abstract}

\section{Keywords}

Pedagogy, Interpreting Teaching, Flipped Interpreting Teaching Mode

\section{Introduction}

Entering the new millennium, teacher-lecturing or information-delivering within the class time still seems to be the main interpreting pedagogy, though some extra activities may be designed and carried out within the very limited time left. Many restraints have been reflected in traditional teaching. First of all, most universities or colleges can only provide 2 to 4 class hours each week for fundamental interpreting courses, which will be attended by 20 - 30 students, or even 40 - 60 students at the same time. Thus, in such circumstances, it's very difficult to cultivate qualified interpreters. Secondly, students' self-learning awareness 
and ability need to be enhanced for the preparation of future interpreting tasks (Wang, 2015b: p. 59).

The fast-developed information and telecommunication technology and easier access of internet worldwide have enriched the teaching and learning methods, including "blended learning, a combination of face-to-face and online teaching and web-based learning" (Sandrelli \& Jerez, 2014; Ligorio et al., 2006), whose connotation more or less overlaps with "inverted classroom" (Lage et al., 2000) and "flipped classroom". Roehl, Reddy, \& Shannon (2013) define "flipping classroom" as a way to "free class time from lecture" for "an expanded range of learning activities during class time" by employing "accessible technology". According to Bergmann \& Sams (2012), "flipped classroom" is "redirecting attention away from the teacher and putting attention on the learner and the learning", which suggests a shift of teaching method from "teacher-centered" to "students-centered". Mok (2014) flips the programming course, allowing more in-class time for pair-programming activities and winning the students' positive feedbacks. Abeysekera \& Dawson (2015) propose that "flipped approaches might improve student motivation and help manage cognitive load" and called for more research on its effectiveness. Kim (2017) explores the effective strategies for flipped interpreting course by comparative study, finding that the "the instructor's role", "practice-oriented modules", "social presence" and "teaching presence" should be maintained or even enhanced in designing and implementing the flipped interpreting class. Wang (2015a) reforms the interpreting course with the help of Moodle, constructing the training model of interpreting skills.

From the above, it can be found that "flipping classroom" has been widely applied into various disciplines in different nations, with the focus ranging from the theoretical construction of flipped teaching to empirical researches on its effectiveness. Despite the increasing popularity of flipped classroom in China, little research has been done on flipping interpreting courses, which is not in line with the national educational strategies. According to the latest China's teaching quality standards for regular undergraduate education, students who are majoring in foreign languages should be able to use the language, appreciate literature, develop the abilities of cross-cultural communication, critical thinking, research, innovation, information technology application, practice as well as self-learning (Advisory Board under the Ministry of Education, 2018). It can be judged that information technology application and self-learning abilities are also stressed for English-learning students, so flipped teaching should be applied to more courses including interpreting course to explore an effective way to reach the national standards.

\section{The Status Quo of Current Interpreting Teaching in China}

\subsection{Methodology}

Questionnaire Survey is the main method used for exploring the status quo of 
the interpreting teaching mode in China. The reason why this questionnaire is designed is as follows. Though teaching reform has been attached great significance in China, the pedagogy for fundamental courses for interpreting is still traditional, the combination of teacher-delivering and in-class practices. Interpreting, a practice-oriented course type, requires students to spend more time on practice and teachers more energy on guidance. However, the detailed introduction of the interpreting skills leaves little time for in-class interpreting or skill practice. Therefore, it is difficult to improve students' interpreting ability, especially those who couldn't timely catch up with the teacher or those lacking self-learning and self-control abilities. As for traditional classroom teaching and flipped interpreting teaching, which one can be more easily accepted and more favored by students? Therefore, against this backdrop, a questionnaire about the interpreting teaching mode preference is designed for students who are learning interpreting. The questionnaire consists of 9 questions, involving the teaching modes of their teachers for fundamental interpreting courses, the students' preference over the teaching methods and reasons, as well as students' evaluation on self-learning about online courses and flipping interpreting courses. After being posted on wjx.cn, a major online survey platform, a total of 159 effective questionnaires have been collected, covering undergraduates and postgraduates in Sichuan, Chongqing, Guangdong and Xi'an.

\subsection{Findings and Discussion}

All the research findings of this section are all derived from the questionnaire survey. The research findings of teaching modes preference among interpreting teachers are shown in Graph 1. For fundamental interpreting courses, $78.62 \%$ of the participants think that their interpreting teachers lay emphasis on theoretical and skill explanation, and interpreting skill practice is taken as a supplementary part. Only $4.4 \%$ of the participants believe that lecturing by the teaching is the predominant teaching mode which usually leaves little or no class time for interpreting or skill practice. The rest $16.98 \%$ participants choose that their teachers try new ways to give interpreting class, but the ways that are listed are listening-oriented or practice-oriented, which still fall to the category of traditional modes.

Students' preference over the interpreting teaching modes and possible reasons are clearly displayed in Graphs 2-4 which are listed below. It can be found in Graph 2 that the majority of the participants (65.41\%) dislike the traditional way of teaching with regard to fundamental interpreting courses while $34.59 \%$ prefer the traditional teaching mode. For those participants who choose dislike (displayed in Graph 4), they mainly think that the remaining class time after teachers' lecturing are too limited for them to have real practice and concrete instructions. They also hold that the traditional way of teaching can only offer low opportunities of class participation, and the mode cannot meet the demands of online learning in this Internet era. For those who choose like (illustrated in 


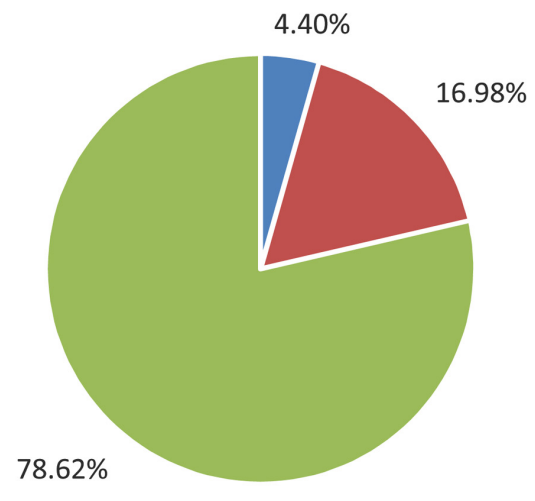

- The interpreting teacher stress on theoretical and skill explanation

- The interpreting teacher tries new teaching mode, which are

- The interpreting teacher combine theory and skill explanation with in-class interpreting activities.

Graph 1 . The teaching modes adopted by teachers regarding fundamental interpreting courses.

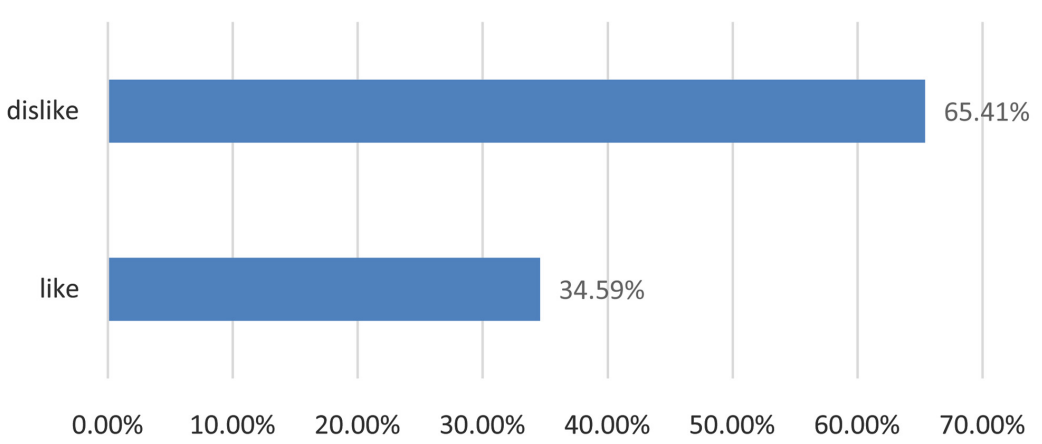

Do you like traditional interpreting teaching mode?

Graph 2. Students' preference over the traditional teaching mode.

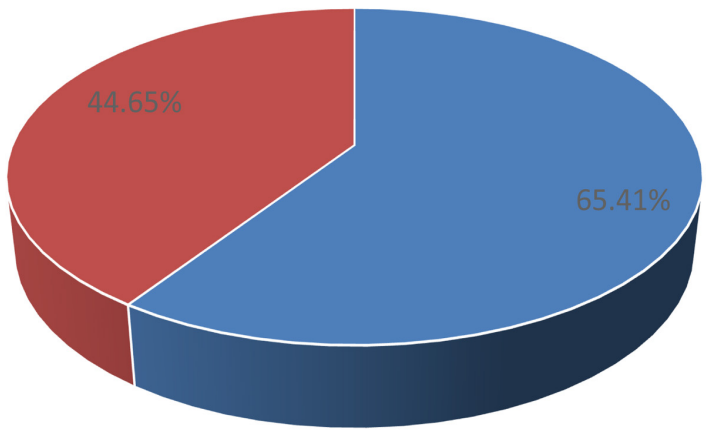

- Traditional interpreting teaching mode can inform students with detailed interpreting theories and skills.

- Passive listening in traditional interpreting class makes students more relaxed.

Graph 3. The reasons why students prefer traditional interpreting teaching mode.

Graph 3), 65.41\% of the participants believe that details about interpreting theories and skills can be provided through traditional way of teaching, and some others think they are used to such way of teaching and passive learning.

The present study has also done a research on participants' preference over 

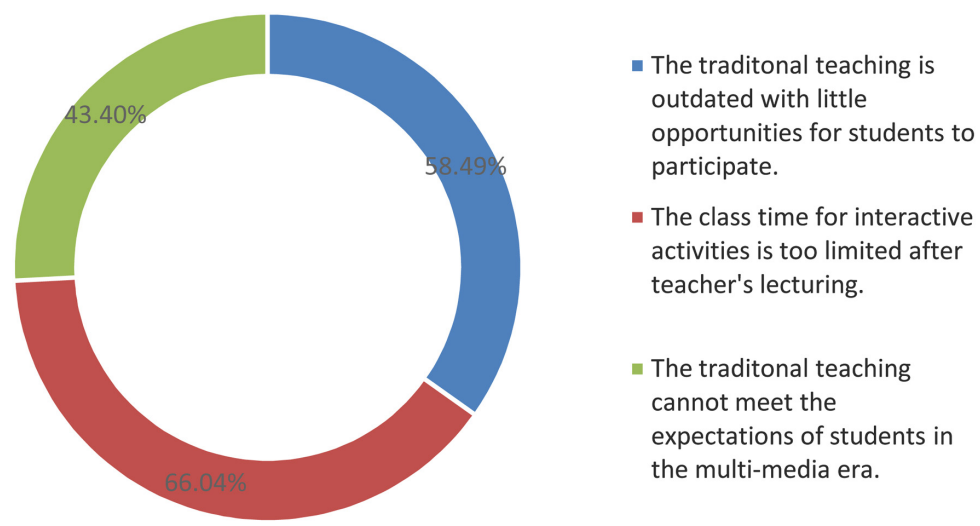

Graph 4. The reasons why students dislike traditional interpreting teaching mode.

online self-learning and the pedagogy of flipping interpreting courses. As is illustrated in Graph 5 listed below, $57.86 \%$ of the participants like to make use of online courses to enrich themselves while $42.14 \%$ dislike. Graph 6 shows that $83.65 \%$ of the participants hope that their teachers could flip the fundamental interpreting courses, and only $16.35 \%$ don't like the flipping pedagogy. Through Graph 7, it can be seen that the strengths of the flipping pedagogy outweigh the weaknesses. The majority (78.62\%) of the participants believe flipping interpreting courses can save much more time for class activities or practices, effectively using students' extracurricular time and the limited class hour. $70.44 \%$ of the participants hold that flipping interpreting courses can be more interesting and interactive. $29.56 \%$ see that they cannot obtain detailed information through the flipping pedagogy, and $25.16 \%$ would not like to sacrifice their extracurricular time for learning.

Generally speaking, the survey indicates that most students favor the flipping pedagogy more than the traditional teaching mode with regard to the fundamental interpreting courses, for they think the flipping pedagogy has more advantages, such as more interactive time for guidance or instruction and so on.

\section{Construction of Flipped Interpreting Teaching Mode in Multi-Media Environment}

The above research findings also prove the current researcher's prediction, which is made base on the interpreting teaching experience for almost a decade. Through the observation, most students in common universities still need to enhance their bilingual proficiency, including vocabulary load and encyclopedia knowledge, and, meanwhile, sharpen their interpreting skills such as active listening, short-term memory, note-taking, public speaking and figure switching and so on.

However, improvement of bilingual proficiency and explanation of interpreting skills can take up a large part of the class time, so they can be flipped to be the pre-class self-learning activities. Apart from watching the videos posted online before the class, the students are also required to finish the designated tasks, 


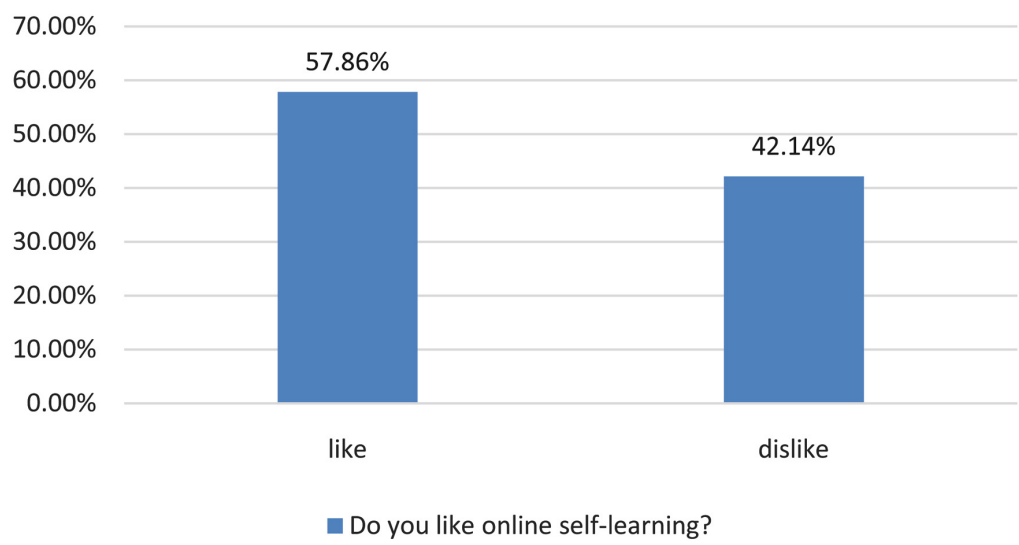

Graph 5. Students' preference over online self-learning.

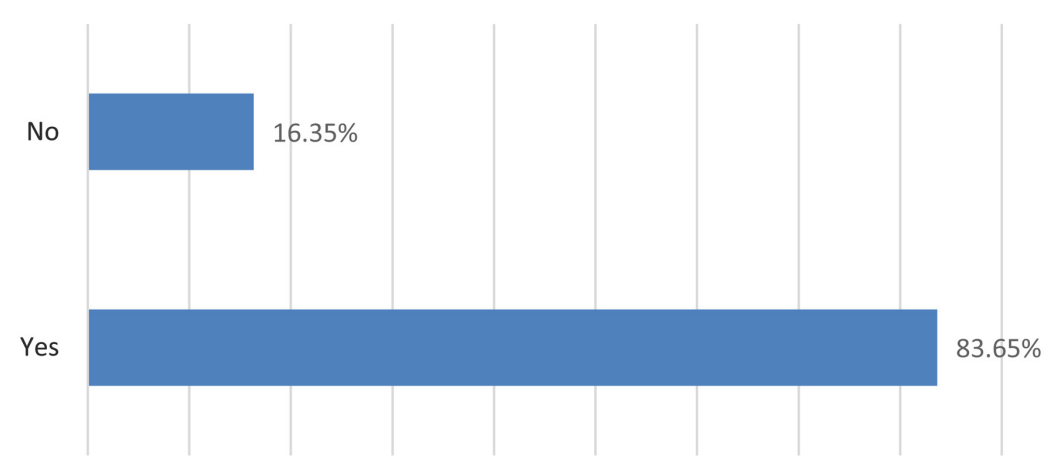

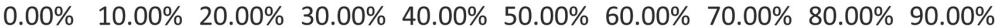

Do you hope that flipping teaching could be adopted in interpreting courses?

Graph 6. Students' preference over flipping interpreting courses.

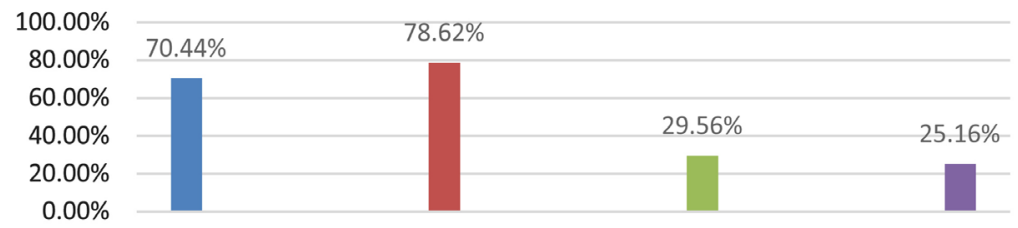

\footnotetext{
- Flipping interpreting classroom can be more interesting and interactive.

Elipping interpreting classroom can use the in-class time much more effeciently,solving the problem of class-hour insufficient.

alipping interpreting classroom cannot inform students as detailedly and clearly as the traditional teaching mode.

- Flipping interpreting classroom will cost students more spare time than the traditional teaching mode.
}

Graph 7. Participants' evaluation on flipping interpreting courses.

which will be checked during the offline class. This is the general design of the first module. During the second module, students' online self-learning effects will be examined and scored. More class time can be used to have specific interpreting skill practices and mock interpreting practices relevant to the theme of 
pre-uploaded videos. After-class tasks should also be designed as the third module to strengthen students' interpreting abilities, such as self-evaluation about in-class mock interpreting and skill or interpreting exercises, etc. The above-described flipping mode can be displayed in the following Graph 8.

\section{Conclusion}

In today's fast-developed internet era, the traditional interpreting teaching mode cannot catch up with the times and meet the requirements of students, so with the advent of MOOCs and mini-lectures, flipped teaching mode is gaining increasing popularity worldwide. The improvement of interpreting ability needs a lot of practice, and flipping interpreting courses can help to free more class time for interpreting practices and teachers' instructions. The research findings also show that participants would like to choose the flipped teaching mode than the traditional one, thus a flipped teaching mode is established for further experiment. In carrying out the flipped teaching experiment, student motivation in pre-class online learning should be emphasized to guarantee the learning effects, which is an extremely key point. Just as Abeysekera \& Dawson (2015) put forward that "flipped classroom approaches wager the success of in-class activities on the likelihood of students completing their pre-class assigned work. This leads to the perennial problems of student preparation: how do teachers know if students have prepared, what they know and if the preparation was useful?" Therefore, a detailed evaluation and testing system should also be considered to guarantee the success of the flipped interpreting pedagogy.

\section{Acknowledgements}

This work is sponsored by Sichuan Foreign Language Literature Research Center and Shanghai Foreign Language Education Press (Project Number: SCWYH18-13; Project Name: Research on Flipped Interpreting Teaching and Testing Based on Post-Method Concept), Education and Teaching Research and Reform Projects of Sichuan University of Arts and Science (Project Number:

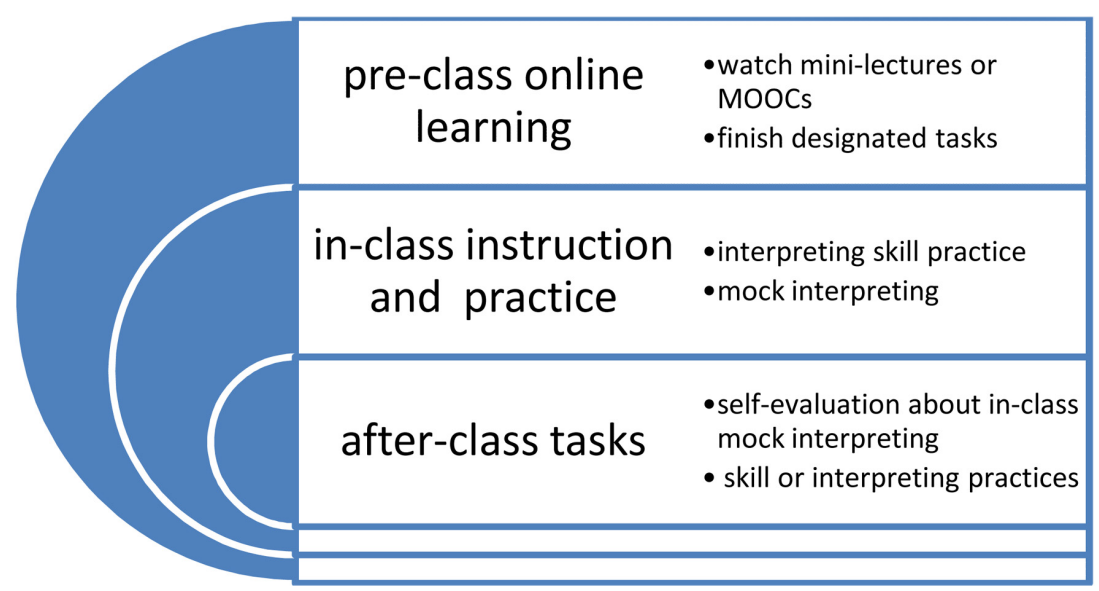

Graph 8. Flipped interpreting teaching mode. 
2017JY11; Project Name: Construction of Flipped Interpreting Mode and Testing Mechanism for BTI).

\section{Conflicts of Interest}

The authors declare no conflicts of interest regarding the publication of this paper.

\section{References}

Abeysekera, L., \& Dawson, P. (2015). Motivation and Cognitive Load in the Flipped Classroom: Definition, Rationale and a Call for Research. Higher Education Research \& Development, 34, 1-14. https://doi.org/10.1080/07294360.2014.934336

Advisory Board under the Ministry of Education (2018). National Teaching Quality Standards for Regular Undergraduate Education. Beijing: Higher Education Press.

Bergmann, J., \& Sams, A. (2012). Flip Your Classroom: Reach Every Student in Every Class Every Day. Washington DC: International Society for Technology in Education.

Kim, D. (2017). Flipped Interpreting Classroom: Flipping Approaches, Student Perceptions and Design Considerations. The Interpreter and Translator Trainer, 11, 38-55. https://doi.org/10.1080/1750399X.2016.1198180

Lage, M. J., Platt, G. J., \& Treglia, M. (2000). Inverting the Classroom: A Gateway to Creating an Inclusive Learning Environment. The Journal of Economic Education, 31, 30-43. https://doi.org/10.1080/00220480009596759

Ligorio, M., Cacciamani, S., \& Cesareni, D. (2006). Blended Learning. Milano: Carocci.

Mok, H. N. (2014). Teaching Tip: The Flipped Classroom. Journal of Information Systems Education, 25, 7.

Roehl, A., Reddy, S. L., \& Shannon, G. J. (2013). The Flipped Classroom: An Opportunity to Engage Millennial Students through Active Learning. Journal of Family and Consumer Sciences, 105, 44. https://doi.org/10.14307/JFCS105.2.12

Sandrelli, A., \& Jerez, J. D. M. (2014). The Impact of Information and Communication Technology on Interpreter Training: State-of-the-Art and Future Prospects. The Interpreter and Translator Trainer, 1, 269-303. https://doi.org/10.1080/1750399X.2007.10798761

Wang, H. L. (2015a). Research on Flipped Interpreting Class with the Aid of Moodle. Journal of Zhejiang Wanli University, 2, 20.

Wang, H. L. (2015b). Study on Interpreting Teaching Based on "Flipping the Classroom". Chinese Translators Journal, 36, 59-62. 